\title{
Health symptoms during midlife in relation to menopausal transition: British prospective cohort study @) $(1 \otimes)$ OPEN ACCESS
}

\section{Gita D Mishra honorary senior research scientist and professor ${ }^{12}$, Diana Kuh professor and director ${ }^{1}$}

${ }^{1}$ MRC Unit for Lifelong Health and Ageing, University College and Royal Free Medical School, London, UK; ${ }^{2}$ School of Population Health, University of Queensland, Herston, QLD 4006, Australia

\begin{abstract}
Objective To characterise symptoms experienced by women during the transition into natural menopause, to classify women into distinct symptom profiles or trajectories, and to relate these profiles to sociodemographic factors and health behaviours.

Design Nationally representative cohort study.

Setting England, Scotland, and Wales.

Participants 695 women followed-up since birth in 1946 and annually from age 47 to 54 who experienced natural menopause and reported on 20 common health symptoms.
\end{abstract}

Main outcome measure Longitudinal profiles for reported bothersome symptoms.

Results Of 20 individual symptoms, 18 formed into four stable symptom groups: psychological, somatic, vasomotor, and sexual discomfort. Using latent class analyses, all except the somatic group of symptoms showed a clear relation with the timing of menopause for some women. A small proportion of women $(10 \%, n=63)$ had a severe psychological symptom profile that peaked at or in the year after menopause. For vasomotor symptoms, $14 \%$ of women $(n=83)$ had the early severe profile that also peaked around early postmenopause and then declined noticeably; $11 \%$ $(n=67)$ had the late severe profile of bothersome symptoms that increased rapidly in perimenopause and remained high for four years or more after menopause. Women were less likely to have a profile for severe vasomotor symptoms if they were from a non-manual social class (odds ratio $0.79,95 \%$ confidence interval 0.57 to 1.01 ) or had degree level qualifications $(0.37,0.18$ to 0.77$)$. The $14 \%$ of women $(n=85)$ who had the late severe profile for sexual discomfort showed a similar increase in symptoms until menopause, with symptoms persisting after menopause. Married women were more likely to have the late severe or late moderate profile than women of other marital status $(2.40,1.30$ to 4.41 ). Four profiles each were identified for somatic symptoms (mild, moderate, severe, and very severe), although these did not vary by chronological age or age at menopause.

Conclusion Profiles for psychological, vasomotor, and sexual discomfort symptoms relative to age at menopause could help health professionals to tailor their advice for women with natural menopause.

\section{Introduction}

Menopause, which marks the end of the reproductive phase of a woman's life, coincides with a range of symptoms experienced during midlife. For some symptoms, such as hot flushes and cold or night sweats (vasomotor symptoms) and vaginal dryness, the relation with menopausal transition is well established. ${ }^{12}$ For other symptoms, such as headaches and joint pain, the findings have been mixed. ${ }^{3}$ Many studies have relied on cross sectional data so that links with menopausal transition have been difficult to disentangle from those due to ageing. ${ }^{1}$ For all symptoms little research has been done on whether subgroups of women with similar longitudinal symptom profiles or trajectories exist and how these relate to the timing of the menopausal transition or change with age.

Understanding the course of vasomotor and other symptoms through midlife and how they relate to the menopause would help health professionals to inform women on the possible duration and variation in severity of symptoms through the menopausal transition. Even with longitudinal studies the results are often reported as mean prevalence of symptoms before and after menopause across the sample, which may obscure the underlying variability in scores across individual women and across groups of women within a sample. ${ }^{2-6}$

Previous research using data from the Medical Research Council National Survey of Health and Development, a population based study, has shown that reported health symptoms at age 47 years tend to cluster into vasomotor symptoms such as hot flushes 
and cold night sweats, somatic symptoms such as headaches and muscle and joint pain, and psychological symptoms such as anxiety and depression. ${ }^{7} \mathrm{We}$ used longitudinal data from the Medical Research Council's survey to characterise the various symptoms experienced by women who had a natural menopause at age 48 to 54 . We identified groups of symptoms that correlate over time, used latent class analysis to classify women into distinct profiles or symptom trajectories through menopause for each symptom group, and identified the links between sociodemographic factors and health behaviours and the symptom profiles.

\section{Methods}

The Medical Research Council National Survey of Health and Development (also known as the 1946 British birth cohort study) is a longitudinal study of health based on a random sample of 5362 singleton births in England, Scotland, and Wales during the first week of March 1946 and stratified on social class. A total of 2547 women and 2815 men were followed up up to 22 times between birth and age 53 years. The cohort is still generally representative of the population born in Britain at that time. ${ }^{8}$ From 1993-2000, when cohort members were aged 47-54, a postal questionnaire was sent annually to the 1778 (70\%) women with whom there was then contact to collect information on health symptoms, the menopause, and change in life circumstances. ${ }^{9}$ During this time a total of 1525 out of 1778 women (86\%) completed at least one questionnaire, including a checklist of health symptoms. This study focuses on the 695 women who were identified as having natural menopause and who completed at least one questionnaire, with 675 women having completed all seven questionnaires. We omitted from these analyses those who had undergone hysterectomy or received hormone treatment.

\section{Results}

Table $1 \Downarrow$ provides descriptive statistics for the women with a natural menopause and reporting bothersome symptoms in the previous year for each symptom item. Across the study period more than one in three of these women reported trouble sleeping, aches and pains in joints, or anxiety and depression (until age 52 years). As a noticeably higher prevalence for all items was evident at age 47 compared with subsequent years, responses at age 47 were omitted from the subsequent latent class analyses. The prevalence of symptoms declined from age 48 to 54 years for half of the items surveyed: breast tenderness, palpitations, dizziness, skin crawling sensations, irritability, anxiety or depression, tearfulness, forgetfulness, and frequent severe headaches. Five symptoms showed an increased prevalence: trouble sleeping, aches and pains in joints, hot flushes, vaginal dryness, and difficulties with sexual intercourse. Other symptoms showed no age related changes: pins and needles in hands and feet, feelings of panic, cold or night sweats, skin wrinkling, and frequency of passing urine.

Factor analysis at each year (see web extra appendix 1 on bmj.com) showed that individual symptoms consistently loaded on to the same factor and in the same order of loading across all years. These four symptom groups were labelled as psychological, comprising trouble sleeping, anxiety and depression, tearfulness, irritability, feelings of panic, and forgetfulness; somatic, comprising aches and pains in joints, pins and needles in hands and feet, dizziness, palpitations, skin crawling sensations, frequent severe headache, breast tenderness, and increased frequency of passing urine; vasomotor, comprising cold or night sweats and hot flushes; and sexual discomfort, comprising difficulties with intercourse and vaginal dryness. The groups for psychological, vasomotor, and sexual discomfort symptoms had a high degree of internal consistency (Cronbach $\alpha>0.8$ ), whereas symptom items were not as clearly identified as being in the somatic symptoms group (Cronbach $\alpha>0.66$ ).

Trouble sleeping cross loaded on to vasomotor symptoms (factor loading $>0.3$ for all years except at age 51 ), but was included in the psychological symptoms group as its factor loadings were consistently higher for this group. The items for hair loss and skin wrinkling had factor loadings of less than 0.3 and were removed from the subsequent analysis.

\section{Psychological symptoms}

For psychological symptoms based on age, latent class analysis resulted in five profiles (fig $1 \Downarrow$ ). Two out of three women $(n=405)$ had mild or moderate symptom profiles with an essentially flat trajectory, whereas $10 \%$ of women $(n=60)$ had very severe symptoms throughout the study period. A further $13 \%(\mathrm{n}=79)$, who had the "recovering severe" profile, had moderate symptoms by the end of the study; conversely, the remaining $10 \%$ of women $(n=63)$ with the onset severe profile started at moderate levels and reported increasingly severe symptoms until age 52 years. When the analysis was repeated relative to age at menopause rather than chronological age (fig 1), similar profiles were identified for the $65 \%$ of women $(n=394)$ with mild and moderate symptoms. Those with the very severe profile then appeared to have a slight peak at the start of postmenopause. The $14 \%$ of women $(n=84)$ who had the recovering severe profile showed a general decline until three years after menopause, whereas those in the onset severe profile started with moderate symptoms that increased to a peak in the first two years of postmenopause and declined back to moderate levels at four years of postmenopause.

\section{Somatic symptoms}

The four profiles identified for the somatic symptom group show a slight decline in prevalence from age 48 to 54 years (fig $2 \Downarrow)$. When the analysis was based on relation to age at menopause, $18 \%$ of women $(n=99)$ were categorised as having the severe or very severe profiles, with symptoms prevalent even in premenopause and persisting through the menopausal transition (fig 2).

\section{Vasomotor symptoms}

Half of the women $(n=343)$ had the mild profile for vasomotor symptoms, whereas $10 \%(n=70)$ were classified as very severe, with chronic bothersome symptoms across midlife (fig $3 \Downarrow$ ). The remaining two profiles showed either diminishing symptoms (early severe profile) or increasing symptoms (moderate profile) until a peak at age 53 years.

When vasomotor symptoms were analysed relative to age at menopause (fig 3 ), the profiles showed a much clearer relation between the prevalence of vasomotor symptoms and the timing of menopause. Almost half of the women $(n=287)$ were classified as having mild symptoms, although in this analysis a slight peak occurred in the year after menopause. The $14 \%$ of women $(n=83)$ who had the early severe profile, already reported bothersome vasomotor symptoms premenopause or three years before menopause, with their symptoms peaking at menopause and then declining steadily in postmenopause. For the $11 \%$ of women $(n=67)$ with the late severe profile, the prevalence of bothersome symptoms increased noticeably during perimenopause to a peak in the year after menopause. A similar trajectory but with a lower severity occurred for the one in four 
women $(n=155)$ who had the late moderate profile, except that the decline in the postmenopausal years was more evident.

\section{Sexual discomfort symptoms}

Analyses for symptoms of sexual discomfort (fig $4 \Downarrow$ ) showed that most women $(>70 \%)$ had the mild profile (no bothersome symptoms). For profiles relative to age at menopause, a minority of women (4\%) were classified as having the very severe profile, with bothersome symptoms throughout the menopausal transition. Ten per cent of women $(n=60)$ had the moderate symptom profile, which declined generally through the menopausal transition. The remaining $14 \%(n=85)$ were classified in the late severe profile, reporting an increasing prevalence of bothersome symptoms of sexual discomfort in late perimenopause through to menopause, with the level of severity persisting for at least four years into postmenopause. Cross tabulation of these profiles showed that $78 \%$ of women $(n=224)$ with the mild vasomotor symptom profile also had mild sexual discomfort, and nearly one in three $(n=27)$ women with late severe sexual discomfort also had late moderate vasomotor symptoms. The latter result is consistent with the similar shape of these two profiles, with both increasing to a peak around the start of postmenopause. Taking all the symptom groups into consideration, $14 \%$ of the women $(n=81)$ had the mildest profile for all four groupings.

\section{Sociodemographic factors and health behaviours}

Women in the somatic and vasomotor symptom groups had similar sociodemographic and health behaviour characteristics to those of the total sample of 695 women (table $2 \Downarrow, \mathrm{P}>0.05$ from $\chi^{2}$ analysis), except for smoking status, where smokers were under-represented in the symptom groups: $108(21 \%) v$ $174(28 \%)$. Women of manual social class or whose father was of the manual social class were more likely to be categorised as having the severe or very severe symptoms profile than were women from the other social classes; women with advanced secondary or degree level educational qualifications were less likely to have the severe or very severe somatic symptoms profile than were women with no qualifications. No association was evident between somatic symptom profiles and body mass index, physical activity level, or smoking status. For vasomotor symptoms, women of non-manual social class, with degree level educational qualifications, non-smokers, and those with a body mass index $\geq 30$ were less likely to have the late moderate or late severe profiles. No associations were found between psychological symptom profiles and sociodemographic factors or health behaviours at age 43 years or earlier (results not shown). Although $80 \%$ of the women were married, marital status was not associated with any of the other symptom groups. For sexual discomfort, married women were more likely to have the severe or late severe profile (odds ratio $2.4,95 \%$ confidence interval 1.3 to 4.4 ) than were women of other martial status.

\section{Discussion}

In this longitudinal study of the symptoms reported by women with natural menopause we identified four stable symptom groups: psychological, somatic, vasomotor, and sexual discomfort. We used latent class analysis to characterise the experience of bothersome symptoms in terms of profiles for each symptom group. The profiles for the somatic symptoms groups had an essentially flat trajectory through midlife and were labelled to reflect the range of bothersome symptoms reported, from mild to very severe. Lower social class and education level were linked with the severe and very severe profiles for somatic symptoms.

When psychological, vasomotor, and sexual discomfort symptoms were analysed relative to age at menopause, a clear relation was observed with the menopausal transition for some profiles. Although two thirds of women reported only mild or moderate psychological symptoms, for the $10 \%$ of women with the onset severe profile, symptoms increased to a peak in the first years of postmenopause before declining. Women who had the early severe profile (14\%) for vasomotor symptoms reported symptoms increasing over the three years before menopause followed by a noticeable decline during postmenopause. This contrasts with the late severe profile $(11 \%)$, where the peak occurred in the first year of postmenopause and remained high over the subsequent three years. Women of a higher social class and educational level, non-smokers, and those with a body mass index of 30 or more were less likely to have the most adverse profiles for vasomotor symptoms. For sexual discomfort, the late severe profile (14\%) showed a steep increase in symptoms leading up to the first year of postmenopause, then reached a plateau for the next three years of postmenopause. The association between married women and the severe profile may reflect a greater awareness of bothersome symptoms of sexual discomfort among such women. More than 1 in 10 of the women (14\%) were classified into the mildest profile for all four symptom groups.

\section{Strengths and limitations of the study}

The strength of this study derives from the use of longitudinal data for a wide range of symptoms reported by a large and well established national birth cohort study that regularly surveyed the women through midlife. Many previous observational studies have been limited to cross sectional analysis, used mean values for the prevalence of specific symptoms, or were restricted to clinic based samples. With our approach of using factor analysis and latent class analysis, we were able to identify the grouping of symptoms and their variation through midlife. This is an exploratory technique, in that it is data driven and does not assume a priori symptom groupings. Confidence in the symptom groupings identified here, however, is strengthened by the confirmatory analysis that indicated their stability over time. The innovative aspect has been to develop profiles based on age relative to menopause rather than chronological age, which permits a more detailed characterisation of symptom profiles and their relation to the menopausal transition.

Although only data from those women who experienced natural menopause were used in this study, it was still possible for them to have had hormone therapy at least two years before menopause or during postmenopause. This was the case, however, only for a minority of women $(n=13)$, and their data do not affect the identified symptom profiles. The links between some sociodemographic factors and health behaviours and bothersome symptoms may result from the differential attrition of the women with hysterectomy or those taking hormone treatment who were excluded from the analyses. Stronger relations may exist between symptom profiles and contemporaneous measures of sociodemographic and health behaviours (rather than baseline measures at age 43 years). All the symptoms are reported and there are no biomarkers. It is the perception of symptoms, however, that may prompt women to visit health professionals.

Repeating the analysis including the 20 women with incomplete responses to questions on symptoms left the results unchanged. Eighty three of the 695 women with natural menopause for 
whom age at menopause could not be determined were thus not included in the analysis for symptom profiles with respect to age at menopause. The women in this analysis, however, had similar sociodemographic factors and health behaviour characteristics except for the proportion of smokers in the sample whose age at menopause was lower.

Unlike the analysis of symptoms based on age, for the profiles at four or more years postmenopause, data on symptoms were available for $335(56 \%)$ of the women. This means there may be marginally less resolution at the end of the analysis, although the main interpretation of findings is based on general characteristics or shape of the profile, such as a progressive year on year decline in symptoms.

We did not exclude women with acute or chronic health conditions or those receiving drugs, which could potentially confound the results, such as the use of antidepressants masking vasomotor symptoms. Their effects, however, would have to alter the characteristics or shape of profiles to substantively affect the main findings.

The prevalence of bothersome symptoms reported at age 47 years was higher than in subsequent surveys, which may be due to a "telescoping" effect because women were asked to report their symptoms for the first time. In the latent class analysis we omitted data on symptoms from the first year to identify profiles. Annual surveys also limit the ability to resolve the timing of events such as menopause with respect to changes in symptoms over a narrower time window, and the length of recall may affect the reporting of the severity of symptoms.

\section{Comparison with other studies}

This study draws on symptoms reported during midlife for a cohort of women born in Britain in 1946 and experiencing a natural menopause; nevertheless the symptom groups-somatic, psychological, vasomotor, and sexual discomfort-essentially match those in previous findings from key studies. ${ }^{16}{ }^{17}$ Latent class analysis was also recently used to identify similar clusters of symptoms in a small study of 103 women, ${ }^{18}$ but not to determine symptom profiles over time. Our finding that only a minority of women in the psychological symptom group have symptom profiles that seem related to the timing of the menopausal transition is consistent with the National Institutes of Health consensus statement that finds only limited or weak evidence for a link between the menopause and mood symptoms and cognitive disturbances, although they identify moderate evidence of a link with sleep disturbances. ${ }^{3}$ Our study adds value by showing that only a minority of women have psychological symptoms related to the menopausal transition. This may explain why evidence from previous studies that took a variable rather than person centred approach may have been inconsistent, especially the contrast between clinic based and population samples. ${ }^{3}$ Similarly, the profiles of somatic symptoms are consistent with most studies that have found no association between menopausal status and somatic symptoms, such as stiff or painful joints. Only the late severe profile for sexual discomfort ( $14 \%$ of the women) seems to be clearly linked to the timing of menopause, which nevertheless is consistent with the consensus view that the prevalence of vaginal dryness increases across the menopausal transition. ${ }^{3} 19$

The association between vasomotor symptoms and the menopause is also well established, but this study adds value by distinguishing an early severe as well as a late severe profile. In a recent review, the authors found that the prevalence of hot flushes varies across menopausal stages, with premenopausal women reporting hot flushes at a far lower although clinically significant rate (median of reported rates was $21.5 \%$ ) than did perimenopausal or postmenopausal women. ${ }^{16}$ This compares with the $14 \%$ of women who were classified in the early severe profile, characterised by the prevalence of bothersome vasomotor symptoms even three years before menopause. Our result that obese women tend not to be classified with moderate or late severe vasomotor symptom profiles is consistent with the known conversion of androgens to oestrogens in body fat. ${ }^{20}$ This contrasts with findings from other longitudinal studies that show higher adiposity associated with reporting of vasomotor symptoms, ${ }^{21} 22$ although the results from these studies are not strictly comparable owing to the different analytical methods used.

\section{Implications of findings}

The symptom profiles identified in this research provide a picture of the variation of symptoms, including any effects of treatments or management strategies, reported by this cohort of women with natural menopause. The findings represent a next step-most notably with the profiles for psychological,

vasomotor, and sexual discomfort symptoms - that if confirmed in other studies and populations can provide health professionals with information to support a more tailored approach to advice and treatment for women. It should be stressed that the classification of symptoms according to profiles is probabilistic, representing the likelihood of a woman following one or other profile. They should be used only as a general guide, rather than for individual prediction, as to the possible trajectory of symptoms in terms of characteristics such as peaks before or after menopause and when symptoms tend to decline or plateau. In practice, a key limitation for profiles based on age relative to menopause lies in the uncertainty of premenopausal and perimenopausal women in knowing at the time of consultation when menopause will occur. Nevertheless, women whose symptoms follow a particular profile may find that the information facilitates decisions on the management of symptoms or the timing of treatment options. Even the understanding for many that their somatic or psychological symptoms are likely to persist through midlife, may alleviate a woman's concerns about the prospect of symptoms worsening through the menopausal transition. The $10 \%$ of women whose psychological symptoms increase from moderate levels during perimenopause (onset severe profile), can be reassured that their symptoms are likely to decline from early postmenopause back to moderate levels.

Once such profiles are established, key points where they diverge can potentially allow health professionals to distinguish the most likely profile that will characterise an individual woman's symptoms. The profiles here suggest that perimenopausal women with bothersome vasomotor symptoms dating back several years (the early severe profile) are likely to experience an increase in severity until menopause. The subsequent decline in prevalence of symptoms in postmenopause may mean that some women would decide management strategies are sufficient. Women with the late severe profile can expect bothersome vasomotor symptoms to last for more than five years in postmenopause; similarly, for women with the severe profile for sexual discomfort. Both types of women present a dilemma for health professionals, since bothersome symptoms are likely to last longer than the duration that is considered desirable for the prescription of hormone treatment. In both cases women may decide that long term management of symptoms is a better option. In contrast, for women with the late moderate profile of vasomotor symptoms, hormone 
treatment for a short period may provide an effective option for alleviating symptoms during the peak in early postmenopause.

\section{Conclusions}

This study presents a picture of reported symptoms from a cohort of women with natural menopause. Longitudinal symptom profiles represent a step forward from standard statistics that describe symptoms during menopause in terms such as average prevalence or duration. These profiles illustrate the different levels of symptom severity and how these track over time, especially in relation to menopause. The approach should be replicated in studies on other populations and cultures, as thresholds for reporting symptoms during midlife may differ. Further research is needed to investigate factors that may affect profiles, including current health status and drug use as well as the symptom profiles of women who have not had a natural menopause. Researchers should also examine the relation between symptom profiles and long term health outcomes, such as the risk of cardiovascular disease. Symptom profiles provide a useful way to translate results from longitudinal studies; over time they may develop as a guidance tool for health professionals.

Contributors: GDM carried out the statistical analysis, interpreted the data, and drafted the manuscript. DK contributed to the study design, interpreted the data, and critically revised the manuscript. Both authors made a significant contribution to the research and the development of the manuscript, approved the final version, and are the guarantors.

Funding: The Medical Research Council provided funding for the National Survey of Health and Development and financial support for DK and GDM. GDM also received funding from the Australian National Health and Medical Research Council.

Competing interests: All authors have completed the ICMJE uniform disclosure form at http://www.icmje.org/coi_disclosure.pdf (available on request from the corresponding author) and declare: no support from any organisation for the submitted work; no financial relationships with any organisations that might have an interest in the submitted work in the previous three years; and no other relationships or activities that could appear to have influenced the submitted work.

Ethical approval: This study was approved by the North Thames multicentre research ethics committee.

Data sharing: No additional data available.
1 Freeman EW, Sherif K. Prevalence of hot flushes and night sweats around the world: a systematic review. Climacteric 2007;10:197-214.

2 Gold EB, Colvin A, Avis N, Bromberger J, Greendale GA, Powell L, et al. Longitudinal analysis of the association between vasomotor symptoms and race/ethnicity across the menopausal transition: study of women's health across the nation. Am J Public Health 2006;96:1226-35.

$3 \mathrm{NIH}$. NIH state-of-the science conference statement on management of menopause related symptoms. NIH Consensus and State-of-the-Science Statements, 2005.

4 Col NF, Guthrie JR, Politi M, Dennerstein L. Duration of vasomotor symptoms in middle-aged women: a longitudinal study. Menopause 2009;16:453-7.

5 Hardy R, Kuh D. Change in psychological and vasomotor symptom reporting during the menopause. Soc Sci Med 2002;55:1975-88.

6 Berecki-Gisolf J, Begum N, Dobson AJ. Symptoms reported by women in midlife: menopausal transition or aging? Menopause 2009:16:1021-9.

7 Kuh DL, Wadsworth M, Hardy R. Women's health in midlife: the influence of the menopause, social factors and health in earlier life. Br J Obstet Gynaecol 1997;104:923-33.

8 Wadsworth ME, Butterworth SL, Hardy RJ, Kuh DJ, Richards M, Langenberg C, et al. The life course prospective design: an example of benefits and problems associated with study longevity. Soc Sci Med 2003;57:2193-205.

9 Kuh D, Hardy R. Women's health in midlife: findings from a British birth cohort study. $J$ Br Menopause Soc 2003;9:55-60.

10 Soules MR, Sherman S, Parrott E, Rebar R, Santoro N, Utian W, et al. Executive summary: Stages of Reproductive Aging Workshop (STRAW) Park City, Utah, July, 2001. Menopause 2001;8:402-7.

11 Muthén BO. Beyond SEM: general latent variable modeling. Behaviourmetrika 2002;29:81-117.

12 Croudace TJ, Jarvelin MR, Wadsworth ME, Jones PB. Developmental typology of trajectories to nighttime bladder control: epidemiologic application of longitudinal latent class analysis. Am J Epidemiol 2003;157:834-42.

13 Nylund KL, Asparouhov T, Muthén BO. Deciding on the number of classes in latent class analysis and growth mixture modeling: a Monte Carlo simulation study. Struct Equ Modeling 2007;14:535-69.

14 Dempster AP, Laird N, Rubin DB. Maximum likelihood from incomplete data via the EM algorithm. J R Stat Soc Series B Stat Methodol 1977;39:1-38.

15 Muthén LK, Muthén BO. Mplus statistical software, release 6. Muthén \& Muthén, 2010.

16 Greene JG. Constructing a standard climacteric scale. Maturitas 1998;29:25-31.

17 Hunter M, Battersby R, Whitehead M. Relationships between psychological symptoms, somatic complaints and menopausal status. Maturitas 1986:8:217-28.

18 Cray L, Woods NF, Mitchell ES. Symptom clusters during the late menopausal transition stage: observations from the Seattle Midlife Women's Health Study. Menopause 2010;17:972-7.

19 Mishra G, Kuh D. Sexual functioning throughout menopause: the perceptions of women in a British cohort. Menopause 2006;13:880-90.

20 Simpson ER, Cleland WH, Mendelson CR. Aromatization of androgens by human adipose tissue in vitro. J Steroid Biochem 1983;19:707-13.

21 Thurston RC, Sowers MR, Sternfeld B, Gold EB, Bromberger J, Chang Y, et al. Gains in body fat and vasomotor symptom reporting over the menopausal transition: the study of women's health across the nation. Am J Epidemiol 2009;170:766-74.

22 Berecki-Gisolf J, Begum N, Dobson AJ. Symptoms reported by women in midlife: menopausal transition or aging? Menopause 2009;16:1021-9.

Accepted: 15 November 2011

\section{Cite this as: BMJ 2012;344:e402}

This is an open-access article distributed under the terms of the Creative Commons Attribution Non-commercial License, which permits use, distribution, and reproduction in any medium, provided the original work is properly cited, the use is non commercial and is otherwise in compliance with the license. See: http://creativecommons.org/licenses/bync/2.0/ and http://creativecommons.org/licenses/by-nc/2.0/legalcode. 


\section{What is already known on this topic}

Only a few symptoms reported by women during midlife have established links with the menopausal transition

Many studies on links between symptoms and menopause report mixed findings, are cross sectional or clinic based, and typically report the prevalence of symptoms as mean value

Little is known about the timing or variation in the severity of symptoms or if subgroups of women exist with similar symptom profiles or trajectories through the menopausal transition

\section{What this study adds}

Four groups of symptoms were identified in women with natural menopause: psychological, somatic, vasomotor, and sexual discomfort Some profiles for psychological and vasomotor symptoms and sexual discomfort showed a clear relation to the menopausal transition Symptom profiles can assist health professionals to tailor their advice for women about the likely severity and duration of their symptoms during menopause

\section{Tables}

\section{Table 1/ Numbers (percentages) of women who reached natural menopause by age 54 years and symptoms experienced during midlife} ( $\mathrm{n}=695$ women)

\begin{tabular}{|c|c|c|c|c|c|c|c|c|c|}
\hline \multirow[t]{2}{*}{ Symptoms } & \multicolumn{8}{|c|}{ Age (years) } & \multirow[t]{2}{*}{$P$ values } \\
\hline & 47 & 48 & 49 & 50 & 51 & 52 & 53 & 54 & \\
\hline Trouble sleeping & $332(47.7)$ & $250(36.0)$ & $265(38.1)$ & $291(41.9)$ & $305(43.9)$ & $320(46.1)$ & $305(43.9)$ & $312(44.9)$ & $<0.001$ \\
\hline Aches and pains in joints & $385(55.4)$ & $281(40.5)$ & $308(44.3)$ & $312(44.9)$ & $318(45.7)$ & $318(45.7)$ & $334(48.1)$ & $322(46.4)$ & 0.005 \\
\hline Breast tenderness & $273(39.3)$ & $161(23.1)$ & $149(21.4)$ & $115(16.6)$ & $111(16.0)$ & $93(13.4)$ & $72(10.4)$ & $59(8.5)$ & $<0.001$ \\
\hline Hot flushes & $221(31.8)$ & $192(27.6)$ & $231(33.3)$ & $223(32.1)$ & $224(32.3)$ & 245 (35.2) & $235(33.8)$ & $235(33.8)$ & 0.04 \\
\hline Palpitations & $184(26.5)$ & $120(17.2)$ & $114(16.4)$ & $102(14.7)$ & $109(15.7)$ & $101(14.5)$ & $94(13.5)$ & $96(13.8)$ & 0.007 \\
\hline Dizziness & $168(24.2)$ & $113(16.2)$ & $97(14.0)$ & $107(15.4)$ & $112(16.1)$ & $98(14.1)$ & $95(13.6)$ & $87(12.5)$ & 0.05 \\
\hline Pins and needles in hands and feet & $161(23.1)$ & $94(13.5)$ & $87(12.5)$ & $100(14.4)$ & $92(13.2)$ & $85(12.2)$ & $90(12.9)$ & $73(10.5)$ & 0.16 \\
\hline Skin crawling sensations & $91(13.1)$ & $74(10.7)$ & $73(10.5)$ & $78(11.3)$ & $59(8.5)$ & $76(11.0)$ & $56(8.0)$ & $57(8.2)$ & 0.05 \\
\hline Irritability & $348(50.1)$ & $238(34.3)$ & $226(32.5)$ & $216(31.1)$ & $191(27.5)$ & $177(25.5)$ & $198(28.5)$ & $164(23.6)$ & $<0.001$ \\
\hline Anxiety and depression & $340(48.9)$ & $258(37.1)$ & $257(37)$ & $245(35.3)$ & $237(34.1)$ & $240(34.6)$ & $222(32)$ & $202(29.0)$ & $<0.001$ \\
\hline Tearfulness & $256(36.8)$ & $191(27.5)$ & $175(25.2)$ & $168(24.2)$ & $154(22.1)$ & $174(25.1)$ & $159(22.9)$ & $145(20.8)$ & 0.003 \\
\hline Feelings of panic & $152(21.8)$ & $120(17.2)$ & $119(17.1)$ & $115(16.6)$ & $104(15)$ & $122(17.6)$ & $103(14.8)$ & $113(16.2)$ & 0.3 \\
\hline Forgetfulness & $287(41.3)$ & $232(33.4)$ & $218(31.3)$ & $224(32.3)$ & $213(30.7)$ & $211(30.4)$ & $199(28.7)$ & $202(29.0)$ & 0.009 \\
\hline Hair loss & $48(6.9)$ & $35(5.1)$ & $34(4.9)$ & $28(4.0)$ & $42(6.1)$ & $40(5.7)$ & $36(5.2)$ & $38(5.4)$ & 0.5 \\
\hline Cold or night sweats & $177(25.4)$ & $141(20.3)$ & $147(21.1)$ & $158(22.7)$ & $158(22.7)$ & $173(24.9)$ & $140(20.2)$ & $132(19.0)$ & 0.8 \\
\hline Skin wrinkling & $111(15.9)$ & $83(12.0)$ & $74(10.6)$ & $70(10.1)$ & $73(10.5)$ & 79 (11.3) & $81(11.6)$ & $93(13.4)$ & 0.16 \\
\hline Vaginal dryness & $136(19.6)$ & $83(12.0)$ & $107(15.4)$ & $98(14.1)$ & $117(16.8)$ & $124(17.9)$ & $129(18.5)$ & $125(18.0)$ & $<0.001$ \\
\hline Difficulties with sexual intercourse & $83(11.9)$ & $67(9.6)$ & $77(11.1)$ & $81(11.6)$ & $90(12.9)$ & $110(15.8)$ & $114(16.4)$ & $115(16.6)$ & $<0.001$ \\
\hline Increased frequency of passing urine & $147(21.2)$ & $120(17.2)$ & $122(17.6)$ & $113(16.2)$ & $133(19.1)$ & $137(19.7)$ & $124(17.9)$ & $136(19.5)$ & 0.2 \\
\hline Frequent severe headache & $190(27.4)$ & $147(21.1)$ & $124(17.9)$ & $126(18.2)$ & $115(16.6)$ & $99(14.3)$ & $97(14.0)$ & $79(11.3)$ & $<0.001$ \\
\hline
\end{tabular}

*Symptoms that bothered participants a little and a lot in previous 12 months.

†Test of trend using data from women aged 48 to 54 years. 


\begin{tabular}{|c|c|c|c|c|c|c|c|c|c|c|c|c|}
\hline \multirow[b]{2}{*}{ Characteristics } & \multirow[b]{2}{*}{$\begin{array}{l}\text { No (\%) } \\
(n=695)^{*}\end{array}$} & \multirow[b]{2}{*}{$\begin{array}{c}\text { No } \\
(n=592) \dagger\end{array}$} & \multicolumn{3}{|c|}{ Profiles of somatic symptoms } & \multirow[b]{2}{*}{$\begin{array}{l}\text { Odds ratio } \\
(95 \% \mathrm{Cl}) \neq\end{array}$} & \multirow[b]{2}{*}{$\begin{array}{c}P \\
\text { value }\end{array}$} & \multicolumn{3}{|c|}{ Profiles of vasomotor symptoms } & \multirow[b]{2}{*}{$\begin{array}{l}\text { Odds ratio } \\
(95 \% \mathrm{Cl}) \neq\end{array}$} & \multirow[b]{2}{*}{$\begin{array}{c}P \\
\text { value }\end{array}$} \\
\hline & & & Mild & Moderate & $\begin{array}{c}\text { Severe/very } \\
\text { severe }\end{array}$ & & & Mild & $\begin{array}{l}\text { Early } \\
\text { severe }\end{array}$ & $\begin{array}{c}\text { Late } \\
\text { moderate/late } \\
\text { severe }\end{array}$ & & \\
\hline $\begin{array}{l}\text { Childhood social } \\
\text { class: }\end{array}$ & & & & & & & 0.002 & & & & & 0.17 \\
\hline Manual & $375(57)$ & 280 & 38.2 & 38.6 & 23.2 & Reference & - & 44.6 & 14.6 & 40.7 & Reference & - \\
\hline Non-manual & $281(43)$ & 239 & 47.7 & 40.6 & 11.7 & $\begin{array}{l}0.60(0.44 \text { to } \\
0.84)\end{array}$ & 0.002 & 50.5 & 13.8 & 35.5 & $\begin{array}{c}0.79(0.57 \text { to } \\
1.01)\end{array}$ & 0.17 \\
\hline Own social class: & & & & & & & 0.03 & & & & & 0.02 \\
\hline Manual & $171(25)$ & 122 & 36.9 & 38.5 & 24.6 & Reference & - & 37.7 & 18.9 & 43.4 & Reference & - \\
\hline Non-manual & $506(75)$ & 411 & 45.3 & 38.9 & 15.8 & $\begin{array}{c}0.65 \text { (0.44 to } \\
0.96)\end{array}$ & 0.03 & 51.1 & 13.1 & 35.8 & $\begin{array}{c}0.65 \text { (0.92 to } \\
0.95)\end{array}$ & 0.02 \\
\hline $\begin{array}{l}\text { Education } \\
\text { qualification: }\end{array}$ & & & & & & & 0.03 & & & & & 0.02 \\
\hline None & $237(36)$ & 171 & 38.0 & 38.6 & 23.4 & Reference & - & 42.7 & 15.8 & 41.5 & Reference & - \\
\hline $\begin{array}{l}\text { Lower } \\
\text { secondary }\end{array}$ & $222(33)$ & 180 & 43.3 & 35.6 & 21.1 & $\begin{array}{c}0.82 \text { ( } 0.55 \text { to } \\
1.21)\end{array}$ & 0.3 & 45.0 & 13.3 & 41.7 & $\begin{array}{c}0.95 \text { (0.64 to } \\
1.42)\end{array}$ & 0.8 \\
\hline $\begin{array}{l}\text { Advanced } \\
\text { secondary }\end{array}$ & $163(25)$ & 134 & 47.8 & 45.5 & 6.7 & $\begin{array}{c}0.54 \text { (0.36 to } \\
0.84)\end{array}$ & 0.01 & 53.0 & 14.2 & 32.8 & $\begin{array}{c}0.68 \text { (0.44 to } \\
1.04)\end{array}$ & 0.07 \\
\hline Degree & $40(6)$ & 36 & 50.0 & 38.9 & 11.1 & $\begin{array}{c}0.55 \text { (0.28 to } \\
1.08)\end{array}$ & 0.08 & 66.8 & 13.9 & 19.4 & $\begin{array}{c}0.37 \text { ( } 0.18 \text { to } \\
0.77)\end{array}$ & 0.008 \\
\hline Body mass index: & & & & & & & 0.3 & & & & & 0.07 \\
\hline 20-24.9 & $358(56)$ & 276 & 44.9 & 39.1 & 15.9 & Reference & - & 44.2 & 16.7 & 39.1 & Reference & - \\
\hline$<20$ & $54(9)$ & 40 & 40.0 & 42.5 & 17.5 & $\begin{array}{c}1.19(0.64 \text { to } \\
2.20)\end{array}$ & 0.6 & 40.0 & 15.0 & 45.0 & $\begin{array}{c}1.22 \text { (0.66 to } \\
2.29)\end{array}$ & 0.5 \\
\hline $25-29.9$ & $144(23)$ & 123 & 41.5 & 39.8 & 18.7 & $\begin{array}{c}1.17(0.79 \text { to } \\
1.73)\end{array}$ & 0.4 & 52.9 & 13.0 & 34.2 & $\begin{array}{c}0.75 \text { (0.50 to } \\
1.13)\end{array}$ & 0.16 \\
\hline$>30$ & $79(12)$ & 59 & 35.6 & 37.3 & 27.1 & $\begin{array}{c}1.65(0.97 \text { to } \\
2.83)\end{array}$ & 0.06 & 62.7 & 6.8 & 30.5 & $\begin{array}{l}0.54 \text { (0.30 to } \\
0.94)\end{array}$ & 0.03 \\
\hline Vigorous activity: & & & & & & & 0.3 & & & & & 0.2 \\
\hline Inactive & $349(55)$ & 268 & 40.3 & 39.6 & 20.2 & Reference & - & 46.6 & 14.9 & 38.4 & Reference & - \\
\hline $\begin{array}{l}\text { At least once a } \\
\text { week }\end{array}$ & $150(23)$ & 119 & 42.9 & 43.7 & 13.5 & $\begin{array}{c}0.81 \text { ( } 0.54 \text { to } \\
1.22)\end{array}$ & 0.31 & 54.6 & 14.3 & 31.1 & $\begin{array}{c}0.73(0.48 \text { to } \\
1.09)\end{array}$ & 0.13 \\
\hline $\begin{array}{l}\text { More than once } \\
\text { a week }\end{array}$ & $142(22)$ & 116 & 49.1 & 33.6 & 17.2 & $\begin{array}{c}0.73 \text { (0.48 to } \\
1.09)\end{array}$ & 0.13 & 45.7 & 12.9 & 41.4 & $\begin{array}{c}1.08 \text { (0.71 to } \\
1.63)\end{array}$ & 0.7 \\
\hline Smoking status: & & & & & & & 0.3 & & & & & 0.02 \\
\hline Current smoker & $174(27)$ & 108 & 38.9 & 40.7 & 20.4 & Reference & - & 38.9 & 14.8 & 46.3 & Reference & \\
\hline Non-smoker & $466(73)$ & 394 & 44.2 & 38.6 & 17.3 & $\begin{array}{c}0.81 \text { (0.54 to } \\
6.3)\end{array}$ & 0.3 & 51.0 & 14.2 & 34.8 & $\begin{array}{c}0.61(0.41 \text { to } \\
0.92)\end{array}$ & 0.02 \\
\hline
\end{tabular}

*Women with natural menopause.

†Women with age at menopause available and who contributed to analysis of symptom profiles relative to age at menopause: mean age at menopause 49.5 (SD 3.5) years.

$\ddagger$ Results from multinomial logistic regression modelling odds of having more severe symptoms profile. 


\section{Figures}
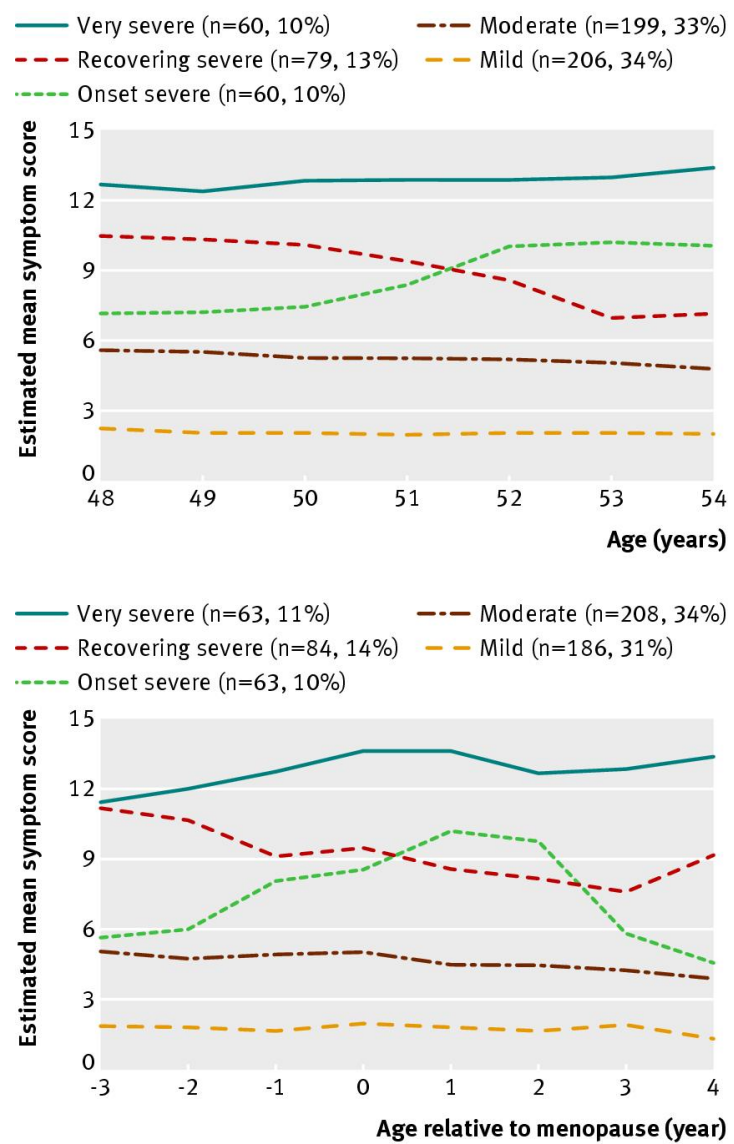

Fig 1 Profiles of psychological symptoms across midlife and according to age relative to menopause 

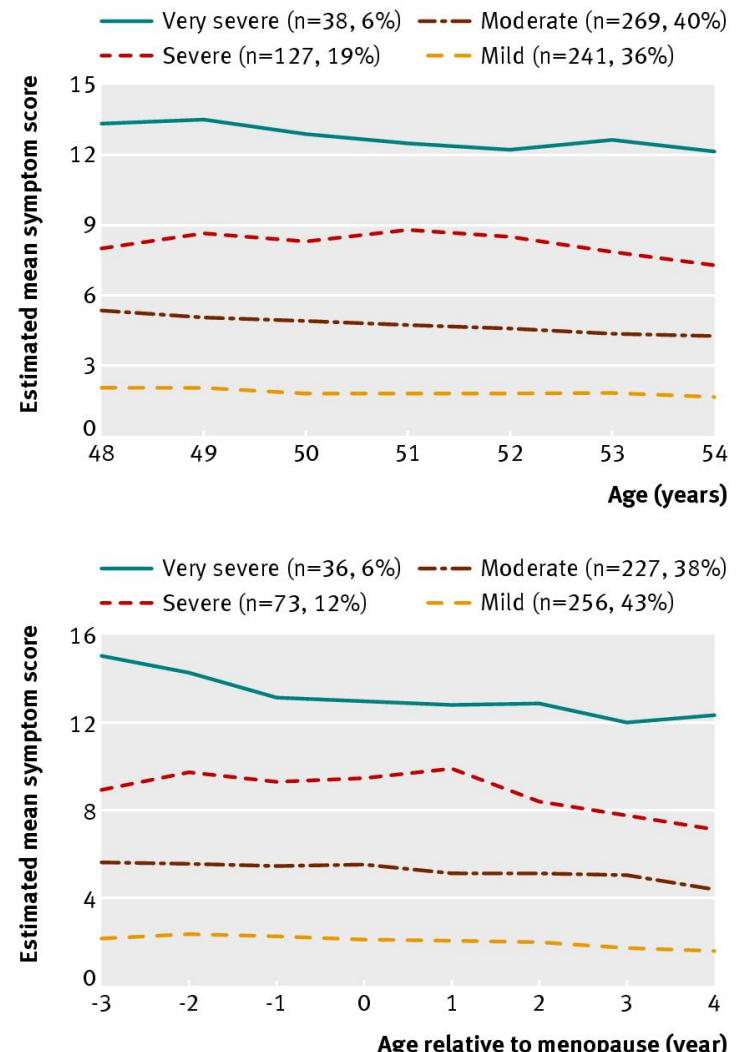

Fig 2 Profiles of somatic symptoms across midlife and according to age relative to menopause
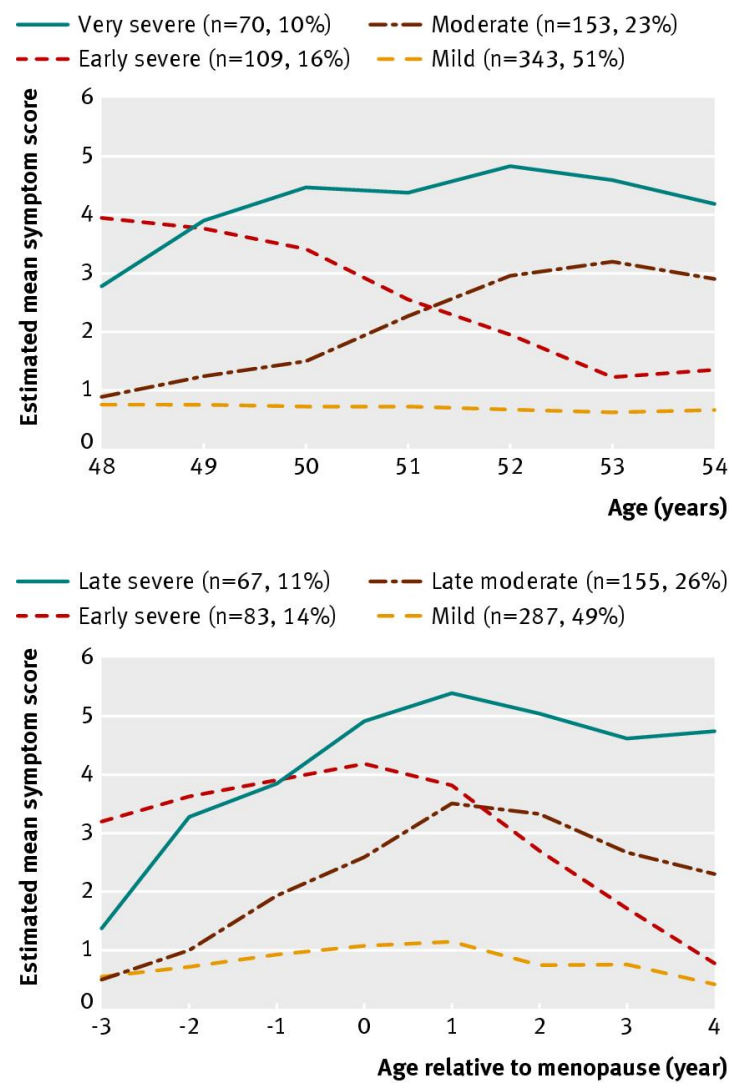

Fig 3 Profiles of vasomotor symptoms across midlife and according to age relative to menopause 

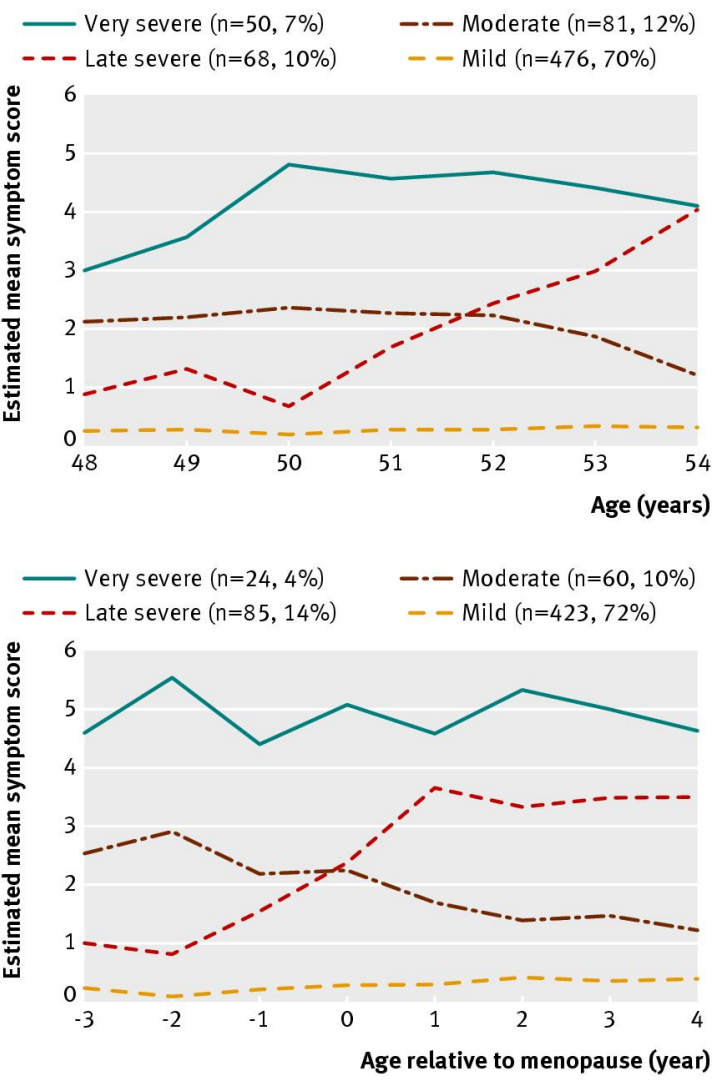

Fig 4 Profiles of sexual discomfort symptoms across midlife and according to age relative to menopause 